Table 3 Relative frequencies of marginal zone lymphomas

\begin{tabular}{lccc}
\hline & $\begin{array}{l}\text { January 1989- } \\
\text { December 1998 }\end{array}$ & $\begin{array}{l}\text { January 2005- } \\
\text { December 2007 }\end{array}$ & p Value \\
\hline MALT lymphoma & $38(19.3)$ & $18(7.9)$ & 0.001 \\
MZL-nodal & $2(1.0)$ & $6(2.6)$ & 0.294 \\
MZL-splenic & $1(0.5)$ & $2(0.9)$ & 1.000 \\
Subtotal & $41(20.8)$ & $26(11.5)$ & 0.008 \\
\hline
\end{tabular}

Data are numbers of cases, with percentages in parentheses.

The comparisons were made by Fisher's exact test; the comparisons for MALT lymphoma and subtotal were by the $\chi^{2}$ test. MALT, mucosa-associated lymphoid tissue; MZL-nodal, nodal marginal zone lymphoma; MZL-splenic, splenic MZL.

reported, also from northern Taiwan, that $17.6 \%$ of their NHLs were FL during 1995 2002. ${ }^{8}$ Their data were probably biased because most of their patients were referred to their institution, a specialised cancer centre, for treatment. Although $17.6 \%$ might not reflect the real frequency of $\mathrm{FL}$, this high rate supports that FL has been increasing in Taiwan in recent years.

In east and south Asia, FL accounts for around $10 \%$ of NHL, while the frequency is around $20 \%$ in Europe, and a third in the USA and Canada. ${ }^{23}$ Biagi and Seymour analysed previously published data to compare $B C L-2$ translocation rates in FL across geographic regions and found that translocation rates were significantly higher for the USA than for Asian populations. ${ }^{3}$ They suggested that the relatively low incidence of FL in Asian populations was caused by distinct molecular pathways from Western populations, and they hypothesised that FL may in fact be a heterogeneous malignancy encompassing entities with distinct molecular pathogenesis and potentially distinct clinical manifestations. ${ }^{3}$ In a previous study of FL, the author and colleagues found that $31 \%$ (20 of 63) cases during 1990-2002 in Taiwan were positive for $B C L-2$ translocation in the MBR. ${ }^{9}$ This rate was lower than that of $65 \%$ in the Western series and supported the hypothesis of Biagi and Seymour that there might be distinct molecular pathogenesis in Western and Asian FLs. ${ }^{3}$

The second significant change during the two periods of time was decreased frequency of MALT lymphoma. The exact cause remains to be elucidated. However, it might be due to the clinical awareness of the association between Helicobacter pylori and gastric MALT lymphoma in recent years in Taiwan, and prompt treatment of $H$ pylorirelated gastric ulcer patients leading to fewer cases of gastric MALT lymphoma, which is the well-known late complication of $H$ pylori-related gastritis. The third significant change is the increased incidence of SLL/ CLL. This increase is probably the result of incorporating flow cytometric immunophenotyping in routine diagnosis since October 2000 in the author's institution rather than a true increase in an incidence of this lymphoma type. Before the introduction of this diagnostic modality, CLL patients were diagnosed and treated solely by haematooncologists and would not enter the ChiMei lymphoma file. Even with the "dilution effect" of SLL/CLL cases in recent years, the frequency of FL during 2005-7 is significantly higher than that in 1989-98.

In conclusion, the relative frequency of $\mathrm{FL}$ in Taiwan has been increasing in the past years toward the higher rate seen in the West, maybe reflecting the changing life style and socio-economic conditions of Taiwan into a developed country. Epidemiological studies, either cross-sectional or longitudinal, incorporating data for surrogate factors reflecting Westernisation, and analytical studies such as case-control/cohort studies, are needed to resolve this issue. Furthermore, molecular studies comparing recent cases and those of one to two decades ago with probes directing at both the $M B R$ and $\mathrm{mcr}$ regions of $B C L-2$ translocation might help to elucidate the molecular mechanisms of FL in Taiwan.

\section{S-S Chuang}

Correspondence to: Shih-Sung Chuang, Department of Pathology, Chi-Mei Medical Centre, 901 Chung-Hwa Road, Yung-Kang City, Tainan County, Taiwan; cmh5301@mail. chimei.org.tw

Acknowledgements: The author greatly appreciates the continuous support from Professor P G Isaacson and thanks Miss C L Lu for statistical analyses.

Competing interests: None.

Accepted 23 April 2008
J Clin Pathol 2008;61:879-880. doi:10.1136/jcp.2008.056242

\section{REFERENCES}

1. The Non-Hodgkin's Lymphoma Classification Project. A clinical evaluation of the International Lymphoma Study Group classification of non-Hodgkin's lymphoma. Blood 1997;89:3909-18.

2. Anderson JR, Armitage JO, Weisenburger DD. Epidemiology of the non-Hodgkin's lymphomas: distributions of the major subtypes differ by geographic locations. The Non-Hodgkin's Lymphoma Classification Project. Ann Oncol 1998;9:717-20.

3. Biagi JJ, Seymour JF. Insights into the molecular pathogenesis of follicular lymphoma arising from analysis of geographic variation. Blood 2002;99:4265-75.

4. Chuang SS, Lin CN, Li CY. Malignant lymphoma in southern Taiwan according to the revised EuropeanAmerican classification of lymphoid neoplasms. Cancer 2000;89:1586-92.

5. Jaffe ES, Harris NL, Stein $\mathrm{H}$, et al. World Health Organization classification of tumours: tumours of the haematopoietic and lymphoid tissue. Lyon: IARC Press, 2001

6. Huang WY, Hsu YH, Yang SF, et al. Primary gastrointestinal follicular lymphoma: a clinicopathological study of 13 cases from Taiwan. J Clin Gastroenterol doi: 10.1097/MCG.0b013e3180f62b12

7. Shih LY, Liang DC. Non-Hodgkin's lymphomas in Asia Hematol Oncol Clin North Am 1991;5:983-1001.

8. Lee MY, Tan TD, Feng AC, et al. Clinicopathological analysis of malignant lymphoma in Taiwan, defined according to the World Health Organization classification. Haematologica 2005;90:1703-5

9. Chuang SS, Hsieh PP, Lu CL, et al. A clinicopathologic and molecular study of follicular lymphoma in Taiwan. Clin Lymphoma Myeloma 2006;6:314-8.

\section{CORRECTION}

doi:10.1136/jcp.2007.047290.corr1

There was an error in an article published in the January 2008 issue of the journal (Nicol AF, Nuovo GJ, Salomão-Estevez A, et al. Immune factors involved in the cervical immune response in the HIV/HPV co-infection. J Clin Pathol 2008;61:84-8). The name of the fourth author was spelt incorrectly. The correct spelling Grinsztejn B. 